\title{
Abstract zu: Schreiben im Kollektiv Martin Mittelmeier und Saša Stanišić im Gespräch mit Ines Barner
}

\author{
Erschienen in: Unterstellte Leseschaften
}

Von: Ines Barner, Martin Mittelmeier, Saša Stanišić

Textarbeit ist einsam und schafft Gemeinschaften, sie vollzieht sich im Privaten und zielt auf einen öffentlichen Resonanzraum. Taugt das, was ich schreibe? Wer wird mich lesen und wie werde ich gelesen werden? Um mit den Unsicherheiten umzugehen, die sich mit dem Übergang von Geschriebenem aus dem privaten Probierfeld in vorläufig Endgültiges, sprich: Publiziertes, verbinden, greifen Schreibende nicht erst seit dem Aufkommen des modernen Buchmarkts auf die Lese- und Mitschreibe-Kompetenzen bestimmter Personen(-Kreise), auf Freund*innen, Kolleg*innen, Verleger*innen zurück.

Mit dem Aufkommen des Lektorats um 1900 wurde eine Begleitinstanz der auktorialen Produktion institutionalisiert. Das Lektorat liest, was geschrieben wurde, es kommentiert und kritisiert, schreibt mit und ,verbessert'. Ob der*die Lektor*in ,nur' rezipiert und Fragen stellt, ob interaktiv an mehr oder weniger gemeinsamen Textentwürfen gebaut wird oder im Feinlektorat nurmehr Kleinigkeiten geschliffen werden - lektorierende Textaktivitäten sind stark kontextabhängig und richten sich nach den Gewohnheiten und Bedürfnissen, dem Wissen und Können ihrer jeweiligen Akteur*innen.

Allerdings wird über das, was zwischen Autor*in und Lektor*in geschieht, üblicherweise geschwiegen. Lektoratsbeziehungen sind Vertrauensbeziehungen; Lektoratsmaterialien wie Briefwechsel oder redigierte Manuskripte sind aus archivarischen und rechtlichen Gründen schwer zugänglich. Erst in jüngerer Zeit erfolgt eine stärkere Öffnung dieser Produktionsbündnisse, werden Gespräche zwischen Autor*in und Lektor*in publiziert und verweisen Autor*innen in Interviews oder in den Büchern selbst auf den Einfluss des Lektorats. So auch Saša Stanišić im Rahmen der Tagung „Unterstellte Leseschaften“ am Kulturwissenschaftlichen Institut, Essen. Stanišićs Hinweis darauf, dass sich seine literarische Produktion stets im intensiven Austausch mit mehreren Mitlesenden und schreibenden vollzieht, war Anlass für ein Gespräch mit dem Autor und dessen Lektor Martin Mittelmeier.

Ines Barner (vormals KWI, seit dem 1. Juni an der ETH Zürich) sprach mit den beiden über Tandem- und Teamarbeit, über das Format Buch und was es braucht, um es zu bedienen, über Schreibschulschriftsteller*innen, die eigentlich als Lektor*innen ausgebildet werden, über das Filtern von Leseschaften und andere Testläufe der 
Literaturproduktion, über die lektorale Suche nach Gründen, schnell weiterblättern zu dürfen, und über Schreiben als Zeitvertreib und unter Beobachtung. Der hier zu lesende Text basiert auf einem Transkript dieses Gesprächs.

SUGGESTED CITATION: Barner, Ines; Stanišić, Saša; Mittelmeier, Michael: Abstract zu: Schreiben im Kollektiv. Martin Mittelmeier und Saša Stanišić im Gespräch mit Ines Barner, in: KWI-BLOG, [https://blog.kulturwissenschaften.de/abstract-zu-schreiben-imkollektiv/], 07.06.2021

DOI: https://doi.org/10.37189/kwi-blog/20210607-0830

\section{Saša Stanišić}

Autor von Romanen und Erzählungen. Zuletzt auch von einem Kinderbuch mit dem Titel „Hey, hey, hey, Taxi!“. Schläft und läuft in Hamburg.

\section{Martin Mittelmeier}

geboren 1971, arbeitete viele Jahre in renommierten deutschen Literaturverlagen und ist seit 2014 als freier Lektor und Autor tätig. 2013 erschien »Adorno in Neapel«, 2016 „DADA«, im Herbst 2021 wird „Freiheit und Finsternis. Wie die ,Dialektik der Aufklärung‘ zum Jahrhundertbuch wurde" erscheinen. Mittelmeier ist Honorarprofessor am Institut für deutsche Sprache und Literatur an der Universität zu Köln.

\section{Ines Barner}

Literaturwissenschaftlerin. Forschungsschwerpunkte: Geschichte, Theorie und Praxis des literarischen Lektorats; kollaborative Autorschaft; Literatur und Archiv; Publikationspraktiken. Nach Stationen in Köln und Basel von Sept. 2019 bis Mai 2021 wissenschaftliche Mitarbeiterin am KWI, ab Juni 2021 Post-Doc an der Professur für Wissenschaftsforschung, ETH Zürich. 
Dieser Text wird via DuEPublico, dem Dokumenten- und Publikationsserver der Universität Duisburg-Essen, zur Verfügung gestellt. Die hier veröffentlichte Version der E-Publikation kann von einer eventuell ebenfalls veröffentlichten Verlagsversion abweichen.

DOI: $\quad$ 10.37189/kwi-blog/20210607-0830

URN: urn:nbn:de:hbz:464-20210607-111826-7 